\title{
Saberes docentes no Ensino de Português Língua Estrangeira: proposta para ação pedagógica
}

DOI: http://dx.doi.org/10.21165/el.v50i1.2902

\author{
Marina Ayumi Izaki Gómez
}

\section{Resumo}

Neste artigo, objetivamos apresentar e discutir os saberes docentes necessários para operacionalizar o ensino de Português Língua Estrangeira (PLE) na prática pedagógica de professores em formação. Levando em consideração que a reflexão é imprescindível na formação de professores, a abordagem reflexiva foi o aporte teórico que fundamentou o estudo. Sob o paradigma qualitativo de base etnográfica e interpretativista, os dados foram analisados considerando o processo de construção de significados. Os participantes são graduandos em Letras, que ministraram cursos de PLE, e a pesquisadora no papel do par mais experiente. Dentre os resultados do estudo, destacamos a necessidade de realizar acompanhamento presencial da prática dos professores em formação e de criar espaços para ampliar reflexão sobre a ação pedagógica, por meio de trabalho colaborativo.

Palavras-chave: saberes docentes; formação de professores; ensino de PLE.

1 Universidade Jaguelônica de Cracóvia (UJ), Cracóvia, Polônia; marinaizaki@gmail.com; https://orcid.org/0000-0001-7762-2500 


\section{Saberes docentes en la Enseñanza de Portugués Lengua Extranjera: propuesta para la actuación pedagógica}

\section{Resumen}

En este artículo, son presentados y discutidos los saberes docentes necesarios en la práctica pedagógica de la enseñanza de Portugués Lengua Extranjera (PLE). Los datos analizados son parte de registros obtenidos en una investigación de doctorado. Este estudio se basa en el enfoque reflexivo dado que su relevancia es significativa en la formación de profesores. Bajo el paradigma cualitativo de base etnográfica einterpretativa, se analizaron datos considerando un proceso de construcción de significados. Los participantes son un investigador (como profesional de PLE con experiencia) y estudiantes de Letras (profesores en formación) que impartieron cursos de PLE. Entre los resultados obtenidos en esta investigación, se destaca la necesidad de una supervisión presencial constante de la práctica pedagógica de los docentes en formación.

Palabras clave: saberes docentes; formación de profesores; enseñanza de PLE.

\section{Introdução}

Dado o atual contexto mundial de crise sanitária, muitas profissões têm ocupado o centro de discussões relacionadas aos serviços altamente necessários para melhor gestão da sociedade nesse momento de confinamento/pós-confinamento. Dentre essas profissões, está o professor. O trabalho desse profissional, muitas vezes desvalorizado, é (re)construído durante e após a sua formação, em um fluxo contínuo de busca e produção de conhecimentos, já que os saberes envolvidos para desenvolver esse ofício são constituídos de outros saberes. Para Tardif (2002), os saberes docentes são plurais e heterogêneos e dificilmente alcançarão a sua completude, pois estão sendo constantemente ressignificados. Nessa perspectiva, o trabalho realizado pelo professor em sala de aula requer a gestão de tarefas multifacetadas de estudo, planejamento, elaboração de atividades/materiais, avaliação, dentre outras, o que demanda formação de qualidade. Transpondo essa reflexão para a área de ensino e aprendizagem de Português Língua Estrangeira (PLE), os desafios podem ser maiores, uma vez que ainda há poucos estudos relacionados com a formação de professores de PLE (DUTRA, 2010) e, por conseguinte, aos saberes docentes por eles construídos.

Para Shulman (1987, p. 11), "uma das tarefas mais importantes para a comunidade de pesquisa é trabalhar com profissionais na prática para desenvolver representações codificadas/sistematizadas da sabedoria didática de professores competentes". Com base nessa premissa, neste artigo, propomos apresentar e discutir saberes docentes necessários para operacionalizar o ensino de PLE na prática pedagógica de professores em formação. Os dados analisados compuseram parte de resultados obtidos em pesquisa 
de doutorado. Levando em consideração que a formação inicial é "uma das fontes das quais se originam os saberes dos professores" (BORGES, 2001, p. 33), investigar a prática de professores em formação pode ampliar a compreensão sobre quais saberes são necessários na ação pedagógica de ensino de PLE. Com esse objetivo, a abordagem reflexiva é o aporte teórico que fundamenta o estudo, pois, reconhecemos que "é pensando criticamente a prática de hoje ou de ontem que se pode melhorar a próxima prática" (FREIRE, 1996, p. 18). Em relação à metodologia, a pesquisa é de natureza qualitativa de base etnográfica e interpretativista e, dentre os instrumentos de coleta de dados utilizados na referida investigação, para este artigo, selecionamos dados registrados no diário do pesquisador e na gravação em áudio das interações do pesquisador com os professores em formação. Os participantes são graduandos em Letras e a pesquisadora no papel do par mais experiente. Como parte dos resultados dessa pesquisa de doutorado, incluímos no presente artigo uma proposta de categorização dos saberes base da prática pedagógica do professor em formação para o ensino de português para estrangeiros.

Este artigo está organizado em quatro partes: fundamentação teórica (discussão sobre abordagem reflexiva e saberes docentes), metodologia (descrição do contexto de coleta de dados e do perfil dos participantes), análise dos dados (categorização de saberes docentes necessários para operacionalizar o ensino de PLE na prática pedagógica) e conclusão.

\section{Fundamentação teórica}

Neste estudo, discussões propostas por Morin (2005) e Charlot (2005) fundamentaram nossa compreensão acerca do saber. Para o primeiro teórico, o conhecimento "não é um espelho das coisas ou do mundo externo [...] sob forma de palavra, de ideia, de teoria, é o fruto de uma tradução/reconstrução por meio da linguagem e do pensamento" (MORIN, 2005, p. 20). Sob viés semelhante, Charlot (2005, p. 45) discorre acerca do saber na sua "relação com o mundo, com o outro e consigo mesmo de um sujeito confrontando com a necessidade de aprender". Com base nessas premissas, não há saber único e isolado, mas em interação constante com o que existe em seu entorno para significar e ressignificar o mundo.

No campo educacional, o saber docente pode ser concebido "como um saber plural, formado pelo amálgama, mais ou menos coerente, de saberes oriundos da formação profissional e de saberes disciplinares, curriculares e experienciais" (TARDIF, 2002, p. 36). O conhecimento transmitido pelas instituições de ensino, direcionado à formação acadêmica, é denominado saber profissional e as disciplinas oferecidas nesse âmbito compõem os saberes disciplinares (TARDIF, 2002). Os programas institucionais de ensino compostos por objetivos, abordagens, metodologias, entre outros aspectos, fazem parte dos saberes curriculares (TARDIF, 2002). Os saberes experienciais estão relacionados com o conhecimento construído durante a experiência do professor, externo à instituição 
formadora, que traduz "um conjunto de representações a partir das quais os professores interpretam, compreendem e orientam sua profissão e sua prática cotidiana em todas as suas dimensões" (TARDIF, 2002, p. 49).

Para Tardif e Raymond (2000), os saberes docentes são construídos socialmente, ao longo da vida, na interação com diversos contextos (familiar, escolar, pré-profissional, profissional). Nesse sentido, os saberes estão em contínua (trans)formação, caracterizando-se como temporais e dinâmicos.

Dentre os saberes docentes propostos por Tardif e Raymond (2000), destacamos os saberes pedagógicos, foco deste estudo. Esses saberes são concebidos como "doutrinas ou concepções provenientes de reflexões sobre a prática educativa [...], reflexões racionais e normativas que conduzem a sistemas mais ou menos coerentes de representação e de orientação da atividade educativa" (TARDIF, 2002, p. 37). Na referida tese de doutorado, os saberes pedagógicos foram (re)construídos e ressignificados em um espaço criado para promover reflexão sobre a prática, por meio da interação do par mais experiente com os professores em formação. A nosso ver, estudos produzidos por Azzi (2009) fortalecem a compreensão sobre esse saber, incluindo o fato de ser construído no dia a dia do professor na sala de aula. Para Azzi (2009, p. 43), a "prática docente é, simultaneamente, expressão desse saber pedagógico construído e fonte de seu desenvolvimento".

Como mencionado anteriormente, Shulman (1987) também considera a prática docente campo significativo de investigação para a área de formação de professores. Esse teórico e sua equipe definem um conjunto de sete saberes para compor os conhecimentos base do professor, incluindo: "Conhecimento do conteúdo; Conhecimento pedagógico geral; Conhecimento do currículo; Conhecimento pedagógico do conteúdo; Conhecimento de aprendentes e suas características; Conhecimento de contextos educacionais; Conhecimento de finalidades, propósitos e valores educacionais, e seus fundamentos filosóficos e históricos" (SHULMAN, 1987, p. 8, tradução nossa²).

De acordo com Shulman (1987, p. 8), o professor deve conhecer o conteúdo que irá ensinar bem como teorias e metodologias de ensino para trabalhar esse "amálgama especial de conteúdo e pedagogia" (conhecimento pedagógico do conteúdo) no processo de aprendizagem do aluno, o que inclui conhecer os aprendentes e suas características. Conhecer o contexto educacional e o currículo de ensino adotado pela instituição amplia a compreensão sobre valores, objetivos, aspectos culturais, econômicos, políticos de escolas e comunidades. Para além do saber teórico e metodológico, a capacidade de

2 No original: "Content Knowledge; General pedagogical knowledge; Curriculum knowledge; Pedagogical content knowledge; Knowledge of learners and their characteristics; Knowledge of educational context; Knowledge of educational ends, purposes, and values, and their philosophical and historical grounds". 
gerenciar e organizar a sala de aula (conhecimento pedagógico geral) também é parte fundante dos sete saberes. Segundo Shulman (1987), à medida que novas discussões são construídas a partir de investigações produzidas sobre a docência, é possível redefinir, repensar os conhecimentos base, por isso, eles não são fixos e imutáveis.

Com base nessas discussões, reconhecemos o quão importante é fomentar ações para o desenvolvimento da reflexão sobre a ação pedagógica. Furió (1994) ressalta a necessidade de formação científica para que o professor possa questionar práticas ou saberes do senso comum. Nesse sentido, promover a reflexão pode ajudar na formação de profissionais potencialmente críticos capazes de avaliarem uns aos outros e a si mesmo. No entanto, o que é reflexão?

Dentre as contribuições apresentadas por Libâneo (2006) acerca do processo de reflexão, destacamos três: o pensar sobre si, o pensar a partir de situação e o pensar dialético. Resumidamente, o primeiro refere-se à autorreflexão, "um exame de consciência sobre os atos praticados, admitindo-se uma realidade interior separada do mundo exterior" (LIBÂNEO, 2006, p. 56). O segundo processo relaciona-se com a interação da ação do indivíduo com o contexto externo, em que há desdobramentos da situação. O terceiro, o pensar dialético, compreende a reflexão sobre a realidade para "construir uma explicação do real" (LIBÂNEO, 2006, p. 56).

Para Schön (2000), o processo de reflexão está relacionado com a ação realizada, que está sendo realizada ou que se realizará. Para esse autor, somos capazes de executar ações complexas sem conseguir explicá-las de forma sistematizada, ou seja, o conhecimento está na ação. Andar de bicicleta é uma das ações exemplificadas por Schön (2000) para esclarecer o conhecer-na-ação: são "ações inteligentes - performances físicas, publicamente observáveis que são reveladas pela nossa execução capacitada e espontânea da performance, e é uma característica nossa sermos incapazes de torná-la verbalmente explícita" (SCHÖN, 2000, p. 31).

Nessa perspectiva, o conhecer-na-ação é "processo dinâmico que exterioriza um conhecimento implícito" (SCHÖN, 2000, p. 31). Uma vez que tentamos sistematizá-lo, transforma-se em conhecimento-na-ação. Ao transpormos essa discussão para a área de ensino de línguas, podemos comparar esse conhecimento implícito com os saberes anteriores à prática, adquiridos/construídos pelo professor que podem ser exteriorizados durante a ação pedagógica.

Ao contrário do conhecer-na-ação, a reflexão-na-ação é um processo de pensar criticamente, construído durante o desenvolvimento da ação para obter resposta imediata. Nesse contexto, a reflexão ocorre em um presente-da-ação (SCHÖN, 2000). Além desses dois processos de reflexão, há a reflexão-sobre-a ação, caracterizada pelo 
ato de pensar retrospectivamente depois da ação (SCHÖN, 2000). Neste estudo, será apresentada a análise de dados construída durante o processo de reflexão-sobre-a ação.

Em relação à área de ensino e aprendizagem, de acordo com Grandcolas e Vasseur (1999), a formação do professor fundamentada na abordagem reflexiva pode propiciar ao futuro profissional o desenvolvimento de sua reflexão sobre o dizer e o fazer. Desse modo, o professor poderá:

[...] ser capaz, de modo autônomo, de analisar a situação de ensino-aprendizagem, de lidar com diferenças interculturais (incluindo as línguas), de adaptar as práticas de ensino ao público diverso e produzir seu próprio material pedagógico (saber recorrer às possibilidades de uso de informática e de multimídia). (GRANDCOLAS; VASSEUR, 1999, p. 5).

Reconhecemos que, de modo complementar, Almeida Filho (2005) também aponta o processo de reflexão como parte integrante no Modelo de Operação Global de Ensino de Línguas. Nesse modelo, as dimensões planejamento de curso, seleção e elaboração de materiais, método (experiência na língua-alvo) e avaliação são construídas por meio de processo reflexivo, orientado pela abordagem de ensino do professor, definida como filosofia de trabalho (ALMEIDA FILHO, 2005).

Ressaltamos o quão importante, e necessário, é desenvolver uma autorreflexão sobre as ações realizadas bem como promover reflexão de modo colaborativo. Para Zeichner (2008), é imprescindível que o processo de reflexão envolva interação social e não seja realizado para si mesmo. De acordo com Kaneko-Marques (2011, p. 60), "a prática pedagógica, mobilizada pela reflexão, serviria como instrumento fundamental para a teorização a partir da prática" e, nesse sentido, no presente estudo, as interações dos professores em formação com o par mais experiente promoveram reflexão colaborativa para a construção de saberes docentes necessários para a ação pedagógica de PLE.

No âmbito deste estudo, a categorização proposta sobre os saberes docentes necessários para a prática pedagógica foi construída na interação do par mais experiente com os professores em formação em um espaço reflexivo, cujo contexto de coleta de dados será explicitado na seção a seguir.

\section{Metodologia}

Os dados que serão apresentados neste artigo fizeram parte de pesquisa de doutorado realizada sob o paradigma qualitativo de base etnográfica e interpretativista. Para Taylor, Bogdan e Devault (2005), o pesquisador qualitativo analisa os dados sob perspectiva holística, ou seja, preocupa-se com o significado construído de modo processual. A 
atividade desse pesquisador requer "um conjunto de práticas interpretativas e materiais que tornam o mundo visível. Essas práticas transformam o mundo. Elas transformam o mundo em uma série de representações" (DENZIN; LINCOLN, 2005, p. 3). Sob esse viés, podemos incluir os instrumentos de coleta de dados como ferramentas que possibilitam a interpretação e a construção de significados.

Em concordância com os propósitos deste artigo, os dados foram coletados por meio de gravação em áudio das interações do par mais experiente com os professores em formação e de diário do pesquisador. Participaram da referida pesquisa 19 professores em formação (denominados PF1 a PF19), 1 pós-graduando (denominado PG20) e a pesquisadora (o par mais experiente).

Os professores em formação são estudantes de Licenciatura em Letras, de uma universidade pública do interior paulista, que cursam disciplina optativa de PLE oferecida pelo Departamento de Letras. A referida disciplina é composta de partes teórica e prática. Na parte teórica, o docente responsável discute, entre outros aspectos, teorias e metodologias de ensino e aprendizagem de PLE e, na parte prática, os professoresestudantes (em dupla) ministram cursos de português para estrangeiros, oferecidos no âmbito de projeto de extensão do departamento, em funcionamento desde 1994. A maioria dos professores em formação não possui experiência no ensino de PLE.

Nos cursos de português para estrangeiros, os interessados podem frequentar as modalidades Básico (níveis 1 e 2), Intermediário (níveis 1 e 2) e Avançado, para falantes de espanhol e falantes de outras línguas. Os participantes dos cursos são, em sua maioria, pós-graduandos de diversas nacionalidades e professores visitantes. Esses cursos ocorrem semestralmente, com carga horária de 45 horas. Além desses cursos, é oferecido o curso preparatório para o Exame Celpe-Bras (Certificado de Proficiência em Língua Portuguesa para Estrangeiros).

A pesquisadora é professora de PLE desde 2007 e realizou investigações na referida área na graduação, no mestrado e no doutorado. No papel de par mais experiente, frequentava as aulas de PLE, ministradas pelos professores em formação, registrando suas observações no diário do pesquisador. Com base nesses registros, o par mais experiente fundamentava as reuniões com os professores.

O diário do pesquisador está organizado em: observações preliminares, observações finais e sugestões. Na primeira etapa, o pesquisador registra suas impressões no início da aula, podendo ser em forma de perguntas. Nas observações finais, há verificação sobre o que de fato ocorreu em sala de aula, o que implica responder ou não às indagações realizadas na fase anterior. Em sugestões, o pesquisador pode sugerir encaminhamentos com base nos registros e discuti-los juntamente com os professores em formação nas reuniões. 
As reuniões com cada dupla de professores ocorriam após realizada a observação da aula ministrada por eles. O objetivo nesse espaço era construir trabalho colaborativo por meio do processo de reflexão entre o par mais experiente e a dupla de professores. A sala de aula da disciplina optativa também se configurou como espaço de reflexão sobre a prática. No entanto, a interação ocorria com todos os professores.

Neste artigo, apresentaremos parte dos dados coletados e dois dos sete instrumentos utilizados na referida tese de doutorado, incluindo o diário do pesquisador e as gravações em áudio das reuniões com os professores.

Conhecido o contexto de coleta de dados, apresentaremos a análise construída no processo de reflexão-sobre-a ação.

\section{Análise de dados}

Nesta seção, apresentaremos três categorias do saber docente propostas na referida investigação, incluindo: saber didático-gerencial, saber interacional-cultural e saber reflexivo-colaborativo.

Com base nas observações realizadas pelo pesquisador nas aulas de PLE, ministradas pelos professores em formação, foram evidenciadas dificuldades de gerenciamento de sala de aula e de aspectos metodológicos de ensino. Dentre os registros no diário do pesquisador, destacamos dados relacionados com o curso Básico 2 para falantes de espanhol:

Quadro 1. Diário do pesquisador (Básico 2 para Falantes de Espanhol)

\begin{tabular}{|c|c|}
\hline PF14 e PF15 - 24/09/2014 & PF14 e PF15 - 15/10/2014 \\
\hline $\begin{array}{l}\text { Observações preliminares: No momento em que } \\
\text { chego à sala, os professores estão discutindo } \\
\text { a canção "Brasil, mostra a sua cara" [...]. Qual é o } \\
\text { propósito da canção? Os alunos possuem muitas } \\
\text { dúvidas relacionadas ao Programa do Básico 1. [...] } \\
\text { Os professores parecem ter dúvidas em relação } \\
\text { ao exercício estrutural selecionados por eles } \\
\text { mesmos. } \\
\text { Observações finais: O propósito da canção foi } \\
\text { trabalhar o Pretérito Perfeito. Os professores } \\
\text { promoveram trabalhos em grupos com os alunos, } \\
\text { o que é muito bom, visto que é uma turma grande. } \\
\text { No entanto, a maior parte da aula está direcionada } \\
\text { às questões gramaticais. }\end{array}$ & $\begin{array}{l}\text { Observações preliminares: A aula tem início com } \\
\text { a correção das atividades da aula passada. Os } \\
\text { alunos possuem muitas dúvidas de vocabulário. } \\
\text { Depois, os professores aplicam um texto para } \\
\text { autoavaliação. Por último, os alunos assistem ao } \\
\text { vídeo sobre a influência da culinária africana na } \\
\text { alimentação brasileira. Qual é o propósito? } \\
\text { Observações finais: Os alunos continuam tendo } \\
\text { muitas dúvidas de vocabulário e a aula é guiada } \\
\text { por essas dúvidas. Falta um pouco de didática e } \\
\text { os professores ficaram sentados a maior parte da } \\
\text { aula. }\end{array}$ \\
\hline
\end{tabular}


Sugestões: Repensar o lugar da gramática na sala de aula: evitar ocupar muito tempo da aula com conjugação de verbos ou com atividades muito estruturais. Elaborar estratégias para tentar amenizar a quantidade de dúvidas com vocabulário (enviar o texto no grupo do Facebook para os alunos pesquisarem possíveis dúvidas). Antes de aplicar uma atividade já existente, tentar fazer para verificar seu funcionamento.
Sugestões: Em relação ao vídeo, faltaram orientações para guiar a atividade de compreensão oral, por exemplo: qual foi o prato sugerido no vídeo, qual é o prato principal, quais são os cuidados para utilizar o dendê? etc. Os alunos somente assistiram ao vídeo.

Fonte: Elaboração própria

Além de outros aspectos de ensino e aprendizagem que podem ser discutidos com base nessas evidências, ressaltamos a importância do conhecimento pedagógico geral e do conhecimento pedagógico do conteúdo propostos por Shulman (1987). Os professores em formação demonstraram dificuldades em gerenciar a sala de aula, devido ao número grande de alunos, e na resolução de atividade selecionada por eles.

$\mathrm{Na}$ aula do dia 24/09/2014, os professores apresentaram dúvidas gramaticais para resolver o exercício e, no dia 15/10/2014, os alunos não receberam instruções/orientações para realizarem a atividade de compreensão oral (trechos destacados no quadro). Nesse sentido, reconhecemos que lidar com as dimensões constituintes do processo de ensino e aprendizagem de línguas é complexo, pois envolve saberes específicos da referida área como planejamento de curso, seleção/elaboração de materiais, método e avaliação. Operacionalizar esse "amálgama especial de conteúdo e pedagogia" (SHULMAN, 1987, p. 8) demanda formação teórico-metodológica e reflexão.

No que se refere à prática em sala de aula, constatamos a necessidade de categorização específica e explícita do saber pedagógico, a qual denominamos saber didático-gerencial que engloba o conhecimento de conteúdo, a metodologia para operacionalizá-lo e a gestão/organização da sala de aula.

A interação do par mais experiente com PF14 e PF15, realizada durante o processo de reflexão após a prática, corrobora a dificuldade desse aspecto de gerenciamento da aula, evidenciada na transcrição a seguir:

Quadro 2. Reflexão após a prática: PF14 e PF15 - Básico 2 para falantes de espanhol

Pesquisadora: Então, eu vou falar um pouquinho da aula que eu assisti, que foi a aula passada. Aí, eu vi que vocês começaram com a música, eu cheguei atrasada na aula, então não posso falar muito. Mas, aí, assim, é que a sua colega [para não dizer o nome da professora que ministra o curso também, optamos por designá-la "colega"] veio perguntar para mim sobre uma atividade, que era para preencher com o verbo haver, aí surgiu uma dúvida em relação àquela atividade, aí eu fiquei me perguntando assim, quando vocês selecionam uma atividade, aquela foi selecionada, vocês não prepararam, vocês pegaram de algum lugar, vocês fizeram antes? 
PF14: Essa eu acho que a gente não fez em tempo.

Pesquisadora: Vocês tentaram fazer por conta própria, justamente, para ver se surge ou não?

PF14: Então, fazer assim de pegar, a gente lê. Mas, não dá para ter essa noção toda quando você está fazendo o exercício.

Pesquisadora: Isso, aí que eu ia sugerir para vocês que toda a atividade que a gente prepara mesmo ou a gente pega atividade pronta, principalmente essas que a gente pega pronta, tenta fazer você ou a sua colega ou os dois juntos para ver se vai surgir algum tipo de dúvida.

PF14: A gente também tá meio inseguro para fazer material, porque no espanhol da universidade, por exemplo, tem uma cobrança que tem que ser tudo original, então, a gente não pode fazer. A gente tem essa insegurança nesse sentido também.

PF14: Acho que o problema também é porque eles falam muito e então qualquer coisinha assim eles dão uma viajada, sabe? Isso é deles, eles falam muito, tentam falar com a gente, falam entre eles, eles falam o tempo inteiro, falando, falando, falando. Não sei se você percebeu isso.

Pesquisadora: Ah, eu percebi sim.

PF14: Às vezes, acontece isso, eles começam a viajar e perguntar uma coisa atrás da outra.

Fonte: Elaboração própria

No trecho em destaque, PF14 relata que o "problema" está no fato de os alunos participarem oralmente de forma excessiva, prejudicando o desenvolvimento da aula. Podemos inferir que PF14 e PF15 não perceberam que essa interação produzida em sala de aula requeria ações pedagógicas dos professores para orientar a atividade. Com base nos pressupostos de Shulman (1987), reconhecemos que o gerenciamento e a organização da aula são aspectos importantes no conjunto dos conhecimentos base do professor e a ausência deles pode dificultar a prática pedagógica, o que implica maior atenção desse fator na formação de professores de PLE.

Outro aspecto que potencializou essa dificuldade no gerenciamento e na organização da aula foi a não reflexão durante o processo de seleção/elaboração de materiais, relatada pelos professores. Como Freire (1996) pontuou, pensar de forma crítica sobre as ações presentes e passadas pode melhorar a prática no futuro. Nesse sentido, a nosso ver, desenvolver a reflexão é imprescindível na formação de professores e requer trabalho constante e presencial por parte do formador.

Durante as reuniões, o par mais experiente pergunta sobre o processo de elaboração de materiais entre os professores, já que foram constatadas a falta de organização da aula e a dificuldade metodológica de trabalhar o conteúdo. A maioria dos professores apontou a falta de tempo. Reconhecemos que a tarefa do professor é complexa, pois envolve áreas de saberes diversos e, portanto, demanda não só formação de qualidade, mas também motivação e esforço do professor em querer melhorar a sua prática constantemente. 
As respostas podem ser visualizadas a seguir:

Quadro 3. Evidências sobre a não reflexão no processo de elaboração de materiais

\begin{tabular}{|c|c|}
\hline Curso & Interação: par mais experiente e professores em formação \\
\hline $\begin{array}{c}\text { Básico } 2 \text { FE } \\
\text { Turma A } \\
\text { (PF } 14 \text { e PF15) } \\
\text { 29/09/2014 }\end{array}$ & $\begin{array}{l}\text { Pesquisadora: Eu queria que você me contasse um pouquinho como vocês } \\
\text { estão lidando assim com o fato de preparar aulas /.../ como vocês estão } \\
\text { dividindo, como vocês estão trabalhando juntos? } \\
\text { PF14: A gente está trabalhando bem juntos, geralmente, a gente se fala por } \\
\text { internet. É tudo meio corrido, aí um vai passando material para o outro, a } \\
\text { gente divide os trabalhos um dia um imprime, às vezes vêm os dois, a gente } \\
\text { vai fazendo como dá assim /.../. }\end{array}$ \\
\hline $\begin{array}{l}\text { Básico } 1 \text { FE } \\
\text { (PF1 e PF4) } \\
14 / 10 / 2014\end{array}$ & $\begin{array}{l}\text { PF 16: Eu penso em seguir o planejamento que fiz. Na verdade, acho que eu } \\
\text { não penso muito [risos]. Eu vejo o plano e aí eu faço em cima do plano e isso } \\
\text { é ruim, porque o que acontece, essa semana eu planejei no sábado, só que } \\
\text { quando chegar no sábado de novo tenho que planejar para segunda e quarta. } \\
\text { Aí é muita correria, o bom de ter apostila é que eu já sei o que vou dar na } \\
\text { próxima aula, daqui a cinco aulas /.../. }\end{array}$ \\
\hline $\begin{array}{l}\text { Básico } 1 \text { FE } \\
\text { (PF1 e PF4) } \\
17 / 10 / 2014\end{array}$ & $\begin{array}{l}\text { PF4: É, a gente tá percebendo que dá muito trabalho. Toda vez que a gente vai } \\
\text { preparar a aula a gente fala "Meu Deus, e agora?" } \\
\text { PF1: Tem que ter tampo. Mas esse semestre a gente já tinha pensado nisso. } \\
\text { Todo mundo já tinha falado que era pesado. } \\
\text { A gente não pagou as literaturas esse semestre para poder se dedicar a essa } \\
\text { matéria. }\end{array}$ \\
\hline $\begin{array}{c}\text { Intermediário } 1 \\
\text { (2012) } \\
\text { (PF10 e PF11) } \\
30 / 09 / 2014\end{array}$ & $\begin{array}{l}\text { Pesquisadora: Então, eu queria perguntar para vocês: como está sendo assim } \\
\text { a preparação do material? Como vocês estão fazendo para se encontrar? } \\
\text { PF10: A gente tomou por base aquele cronograma do Intermediário que você } \\
\text { mandou, a gente mudou algumas coisinhas, e a gente se comunica muito por } \\
\text { e-mail por nossos horários serem diferentes. Mas, pelo menos uma vez por } \\
\text { semana a gente se encontra pessoalmente, para juntar as ideias. } \\
\text { PF11: Nós decidimos que na quarta, que é o horário que temos em comum. } \\
\text { PF10: Livre [risos]. } \\
\text { PF11: Livres [risos] é bem apertadinho inclusive, na quarta-feira, a gente se } \\
\text { encontra e prepara sempre o material da semana [...]. }\end{array}$ \\
\hline
\end{tabular}

Fonte: Izaki Gómez (2018, p. 160)

Com base nesses registros, os professores relatam não ter tempo para se dedicar à preparação de materiais. Além disso, PF16 afırma não pensar muito a respeito. Como discutido anteriormente, o processo reflexivo é altamente necessário na formação de professores, pois permite repensar práticas e saberes relacionados com o ensino e aprendizagem de línguas. Além da importância de desenvolver autorreflexão, como aponta Libâneo (2006), é igualmente profícuo promover reflexão por meio de interações sociais, como defende Zeichner (2008). Nesse sentido, o saber reflexivo-colaborativo também foi proposto como conhecimento integrante dos saberes pedagógicos, 
imprescindível na prática. A ação do par mais experiente no acompanhamento das aulas e no espaço de interação com os professores pode auxiliar na construção de reflexão de modo colaborativo, contribuindo para a formação acadêmica e a atuação profissional.

Em relação ao saber interacional-cultural, foi constatado que lidar com o público de alunos estrangeiros se configurou como desafiador. Os cursos de PLE recebem estudantes de graduação, pós-graduação e professores provenientes de vários países e lidar com esse público pode acarretar outros desafios para os professores em formação. Esse aspecto pode ser averiguado a seguir:

Quadro 4. Público-alvo: alunos estrangeiros

\begin{tabular}{|c|c|}
\hline Na disciplina optativa de PLE & Nas reuniões (reflexão-sobre-a ação) \\
\hline $\begin{array}{l}\text { PF13: /.../ tem um aluno que é canadense e } \\
\text { quis passar para a turma delas /.../ } \\
\text { PF7: e deu certo? } \\
\text { PF1: Então, no início, ele dizia que só falava } \\
\text { francês, e depois começou a misturar as } \\
\text { respostas em francês e inglês /.../. Aí, a gente } \\
\text { foi falando só português /.../ eu acho que ele } \\
\text { foi ficando um pouco bravo, mas /.../ } \\
\text { PF7: Mas. eu acho que é o temperamento } \\
\text { dele } \\
\text { PF4: É, ele tem um temperamento difícil, mas } \\
\text { a gente conseguiu /.../ } \\
\text { PF7: Ele não falava inglês, falava só } \\
\text { português. Quando eu ia me dirigir a ele } \\
\text { em inglês, ele cortava e falava "fale em } \\
\text { português". [outros professores ficam } \\
\text { surpresos]. } \\
\text { PF4: Assim, ele não foi grosso, ele não foi } \\
\text { bravo, mas ele tem uma cara tipo, uma cara } \\
\text { de quem está te avaliando. } \\
\text { Pesquisadora: se eu não me engano ele é } \\
\text { professor. } \\
\text { PF4: De universidade. } \\
\text { PF1: Ele é da área de educação./.../ } \\
\text { Pesquisadora: por isso que o Coordenador } \\
\text { falou que o nosso público é sofisticado. } \\
\text { PG20: Exigente. }\end{array}$ & $\begin{array}{l}\text { Básico } 1 \text { FE Turma A - PF } 14 \text { e PF15, 29/09/2014 } \\
\text { Pesquisadora: /.../ Mas, numa visão geral assim os } \\
\text { desafios para vocês agora? /.../ Pensando agora depois } \\
\text { que vocês conheceram a turma, depois de quase um } \\
\text { mês de aula, o desafio maior de vocês ta aonde? } \\
\text { PF14: Acho que nas coisas práticas assim dar uma } \\
\text { segurada na turma, porque às vezes é difícil, porque a } \\
\text { gente é novo e aí tem a aula que é mais velha e gostar } \\
\text { de falar muito, e daí , como vou interferir sem ser } \\
\text { deseducado. Isso é meio complicado. E acho que ter } \\
\text { uma visão clara assim na preparação do material, do que } \\
\text { é mais pertinente ou não. } \\
\text { Básico } 2 \text { FE Turma B - PF16, 14/10/2014 } \\
\text { PF16: /.../ Também todas as coisas multimídias que eu } \\
\text { uso em sala, eu posto no grupo, mas eles não olham. Na } \\
\text { prova oral, eu fiz uma pergunta dos vídeos que eu havia } \\
\text { postado e do texto que eu havia passado /.../ } \\
\text { Você leu o texto? Que texto? /.../ } \\
\text { Pesquisadora: E você já deu esse feedback para o } \\
\text { pessoal? } \\
\text { PF16: Ainda não, a prova foi ontem [...] Porque o que eu } \\
\text { vejo assim, é que eles acham que eu sou jovem, não sei } \\
\text { o que eles pensam. Eles acham que é brincadeira, eu } \\
\text { preparo as aulas /.../ }\end{array}$ \\
\hline
\end{tabular}

Fonte: Izaki Gómez (2018. p. 170)

Com base nesse relato, dentre outros aspectos possíveis de reflexão, destacamos o desafio de lidar com um público com idade superior à dos professores e as interações construídas no espaço de sala de aula. Shulman (1987) aponta o conhecimento de 
aprendizes e suas características como um dos aspectos fundantes dos conhecimentos base do professor e, a nosso ver, altamente relevante para o processo de ensino e aprendizagem de línguas. Conhecer as necessidades e os interesses dos alunos também faz parte do Modelo Global de Ensino de Línguas, proposto por Almeida Filho (2005), o que requer atenção por parte do professor no processo de planejamento de curso/ aula. Com base no relato de PF16, podemos inferir que os materiais compartilhados em um grupo virtual não "despertaram" interesse dos alunos, o que pode indicar um não conhecimento sobre os estudantes por parte do professor.

No tocante ao "temperamento" do aluno, relatado pelos professores, segundo Charlot (2005, p. 45), a "relação com o saber é a relação com o mundo, com o outro e consigo mesmo de um sujeito confrontando com a necessidade de aprender". Nesse sentido, faz parte da construção do saber estarmos em interação com tudo que nos cerca e durante esse percurso aprendermos a lidar com os desafios. A relação com o outro, no caso do professor com o aluno, colabora para a construção de reflexão sobre o processo de ensino e aprendizagem, o que implica maior atenção sobre a relação interpessoal. Nesse sentido, foi proposto o saber interacional-cultural como constituinte dos saberes necessários para operacionalizar o ensino de PLE na prática e, portanto, a nosso ver, configura-se como fundamental potencializar a sua discussão na formação de professores.

Com base nas observações realizadas na prática em sala de aula dos professores em formação, foi proposto o chamado Saberes base da prática pedagógica para professores em formação no Ensino de Português para Estrangeiros, representados na figura a seguir:

Figura 1. Proposta de categorização de saberes pedagógicos

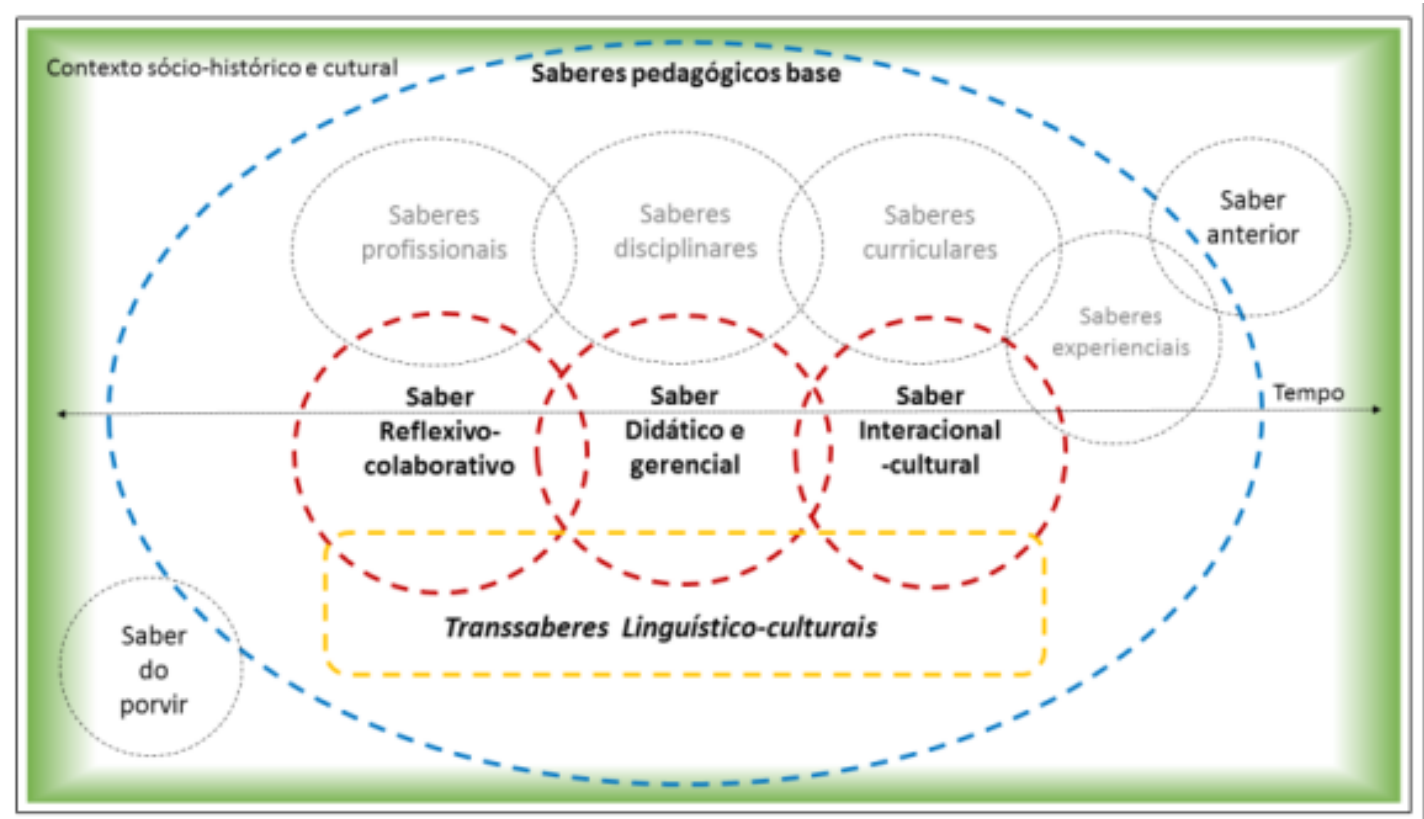

Fonte: Izaki Gómez (2018, p. 193) 
Com base nas informações constantes nessa figura, reconhecemos que cada contexto de ensino e aprendizagem de PLE possui suas especificidades sócio-históricas e culturais, implicando outros desafios. As três categorias de saberes propostas relacionam-se com a prática pedagógica e são constituídas por outros saberes docentes, concebidos como plurais e heterogêneos (TARDIF, 2005). Ao longo de sua experiência, o professor desenvolve um saber anterior que pode ser (re)construído por meio de saberes adquiridos durante a formação acadêmica, incluindo os saberes profissionais, disciplinares, curriculares e experienciais (TARDIF, 2005). De acordo com estudos apresentados na fundamentação teórica, esses saberes não são fixos e imutáveis, ao contrário, estão em constante (trans) formação (TARDIF, 2005; SHULMAN, 1987). Nesse sentido, os saberes reestruturam-se ao longo do tempo, produzindo novos saberes, intitulados saberes do porvir.

Os transsaberes linguístico-culturais indicados nessa figura também foram propostos na referida tese de doutorado com base nos dados analisados. No entanto, optamos por não os apresentar neste artigo, já que não se trata de um saber adquirido formalmente, segundo definição a seguir: "aquele que ensina sua língua materna como idioma estrangeiro pode experienciar situações que transcendem o conhecimento puramente linguístico e que ocorrem quando há interação com outro sujeito pertencente à cultura diferente da sua" (IZAKI GÓMEZ, 2018, p. 176). Nessa perspectiva, esse saber é experienciado/vivido e não adquirido ${ }^{3}$.

Com base nesse contexto, foram propostas três categorias do saber que, no mínimo, os professores em formação precisam para operacionalizar o ensino de PLE na prática, incluindo: saber reflexivo-colaborativo, saber didático e gerencial e saber interacionalcultural.

\section{Conclusão}

Neste artigo, a apresentação e a discussão dos dados analisados apontaram para a necessidade premente de ampliar reflexão sobre a formação de professores de PLE. Durante as interações com o par mais experiente, os professores afirmaram não ter tempo para se dedicar à seleção e elaboração de materiais, acarretando dificuldades que foram evidenciadas na prática. Dentre essas dificuldades, destacamos a falta de gerenciamento e organização da aula e a não reflexão sobre as dimensões constituintes do processo de ensino e aprendizagem de línguas, tais como, o planejamento de curso/ aula, seleção e elaboração de materiais, método (experiências na língua-alvo) e avaliação. Consideramos importante fortalecer a discussão com os professores em formação

3 É como se, nesse momento de interação, o fato de ser "provocado" fizesse com que um saber ainda "oculto" de sua própria língua-cultura se manifestasse. Esse acontecimento é denominado por nós transsaberes linguísticos-culturais sobre a língua materna, ou seja, um conhecimento que transcende o nosso saber acerca da própria língua-cultura, em um movimento que vai "além de". 
sobre o fato de que ministrar um curso de PLE demanda, além dos saberes docentes mencionados, tempo para reflexão sobre os processos de ensino e aprendizagem de línguas.

No que se refere à formação do professor de PLE, reconhecemos a necessidade de realizar acompanhamento constante e presencial da prática e de criar espaços para promover reflexão sobre a ação pedagógica, tendo o par mais experiente como mediador. Esse trabalho colaborativo realizado de modo sistemático pode potencialmente ajudar no desenvolvimento de percepção crítica sobre o saber e o fazer pedagógicos no ensino e aprendizagem de PLE.

Temos expectativas de que a reflexão construída neste artigo possa ampliar a discussão sobre os saberes docentes necessários para operacionalizar o ensino de PLE, dada a escassez de estudos sobre esse tema na referida área.

\section{REFERÊNCIAS}

ALMEIDA FILHO, J. C. P. Dimensões comunicativas no ensino de línguas. São Paulo: Pontes Editores, 2005.

AZZI, S. Trabalho docente: autonomia didática e construção do saber pedagógico. Saberes pedagógicos e atividade docente, v. 4, p. 35-60, 2009.

BORGES, C. Saberes docentes; diferentes tipologias e classificações de um campo de pesquisa. Educação \& Sociedade, Directory of Open Access Journals, v. 22, n. 74, p. 59-76, 2001.

CHARLOT, B. Relação com o saber, formação dos professores e globalização: questões para a educação hoje. Porto Alegre: Penso, 2005.

DENZIN, N. K.; LINCOLN, Y. S. The sage handbook of qualitafive research. Thousand Oaks, CA: Sage Publication, 2005. p. 695-728.

DUTRA, A. F. O processo reflexivo-colaborativo na formação inicial de professores de português língua estrangeira. 2010. Tese (Doutorado em Linguística Aplicada) - Faculdade de Letras, Universidade Federal de Minas Gerais, Belo Horizonte, 2010.

FREIRE, P. Pedagogia da autonomia: saberes necessários à prática docente. São Paulo: Paz e Terra, 1996. 
FURIÓ, C. Tendencias actuales en la formación del profesorado de ciencias. Enseñanza de las ciencias: revista de investigación y experiencias didácticas, v. 12, n. 2, p. 188-199, 1994.

GRANDCOLAS, B.; VASSEUR, M.-T. Conscience d'enseignant, conscience d'apprenant: réflexions interactives pour la formation. [S.I.]: Socrates/lingua, 1999.

IZAKI GÓMEZ, M. Saberes docentes e desafios no ensino de Português Língua Estrangeira na atuação de professores em formação. 2018. Tese (Doutorado em Linguística) - Centro de Educação e Ciências Humanas, Universidade Federal de São Carlos, São Carlos, 2018.

KANEKO-MARQUES, S. M. O processo de (re) construção da prática pedagógica de professores de língua inglesa em formação inicial. 2011. Tese (Doutorado em Estudos Linguísticos) Instituto de Biociências, Letras e Ciências Exatas, Universidade Estadual Paulista, São José do Rio Preto, 2011.

LIBÂNEO, J. C. Reflexividade e formação de professores: outra oscilação do pensamento pedagógico brasileiro. In: PIMENTA, S. G.; GHEDIN, E. (org.). Professor reflexivo no brasil: gênese e crítica de um conceito.4. ed. São Paulo: Cortez, 2006. p. 53-80.

MORIN, E. As cegueiras do conhecimento: o erro e a ilusão. In: MORIN, E. Os Sete saberes necessários à educação do futuro. São Paulo: Cortez; Brasília: UNESCO, 2005. p. 19-31.

SCHÖN, D. A. Educando o profissional reflexivo: um novo design para o ensino e a aprendizagem. Tradução Roberto Cataldo Costa. Porto Alegre: Artmed, 2000.

SHULMAN, L. Knowledge and teaching: Foundations of the new reform. Harvard educational review, Harvard Education Publishing Group, v. 57, n. 1, p. 1-23, 1987.

TARDIF, M. Os professores diante do saber: esboço de uma problemática do saber docente. In: TARDIF, M. Saberes docentes e formação profissional. Petrópolis: Vozes, 2002.

TARDIF, M.; RAYMOND, D. Saberes, tempo e aprendizagem do trabalho no magistério. Educação \& Sociedade, SciELO Brasil, v. 21, n. 73, p. 209-244, 2000.

TAYLOR, S. J.; BOGDAN, R.; DEVAULT, M. Introduction to qualitative research methods: A guidebook and resource. Nova Jersey: John Wiley \& Sons, 2005.

ZEICHNER, K. M. Uma análise crítica sobre a reflexão como conceito estruturante na formação docente. Educação \& Sociedade, Campinas, v. 29, n. 103, p. 535-554, maio/ago. 2008. Disponível em: http://www.cedes.unicamp.br. Acesso em: 16 jul. 2014. 